\title{
Strategies to Train and Improve Students' Composition Creation Ability in Photography Practice Teaching
}

\author{
Yihan Jia ${ }^{1, *}$ \\ ${ }^{1}$ Beijing Institute of Fashion Technology, 100105, Beijing, China \\ *Corresponding author.Email: sxyjiayihan@bift.edu.cn
}

\begin{abstract}
Photography course plays an important role in undergraduate art education and improving undergraduate cultural quality education. The composition of a picture is directly linked to the quality of the works, and the improvement of composition ability is also a teaching difficulty in photography. Therefore, this work mainly expounded the strategies to improve students' composition creative ability through effective training in photography teaching. Firstly, in photography teaching, it should guide students to refine the evaluation criteria of excellent photography works: distinctive theme, highlighting the subject and establishing visual center, concise composition and full of interest. The three points are the essential prerequisites for forming excellent works. Based on the evaluation criteria of excellent works, the students are guided to analyze and classify the targeted composition elements of photographic pictures, forming the elements such as "subject, companion, environment, color" for picture reconstruction. Through designing the main position, skillfully using the guide line and looking for comparison in the picture to reconstruct the picture, this study aim to obtain the excellent picture composition form, and take different topics as the project team to improve the students' composition creation ability in the homework training. Keywords: Composition, Visual center, Guide line, Composition creation, Photographic creation
\end{abstract}

\section{INTRODUCTION}

Photography course is an indispensable course in undergraduate education and teaching in colleges and universities. It plays a vital role in art education and cultural quality education. Photography course can train students' observation ability, aesthetic ability, design ability and thinking innovation ability, and lay a solid foundation and profound humanistic accumulation for their professional creation and long-term development. In the teaching of undergraduate photography course in colleges and universities, there are some difficulties in the shooting and creation of practical teaching. Namely, it is more difficult to master the composition and artistry of photographic works than that of camera operation technology. The quality of the composition for a work is the key to the success of the work. A work with a good composition will mostly succeed. If the composition is improper, no matter how good the idea and technology are, it cannot shoot excellent photography. Therefore, the study of composition is the top priority of photography teaching. Therefore, how to improve the photography composition ability of undergraduates has become the top priority in the course.

Based on the three elements of excellent works, this work divided the subject of photographic picture into four constituent elements according to their roles in the picture: subject, companion, environment and color. Besides, the composition creation ability through different topics according to the role of each constituent element in the picture will be exercised.

\section{THE CONCEPT OF COMPOSITION}

The "composition" is a professional term of plastic arts. It means that, in artistic creation, the composition elements of the picture are rearranged and combined in the picture according to the needs of performance theme and theme expression, and the picture composition form with high aesthetics and artistry is configured. Composition is an important part of visual art modeling. In Cihai, "composition" is regarded as the artist's arrangement and layout of the relationship and position of people and things in a certain space in order to better express the main idea and aesthetic effect of the work, so as to form individual or local images into an artistic whole [1]. Photography is an important part of visual art form, and the composition of photography also reorganizes and distributes the elements and objects, constituting the overall picture in a limited space or plane. Therefore, a picture composition form with aesthetic feeling and artistic conception is formed, and the photographer's creative intention and aesthetic interest is expressed. In the teaching of undergraduate photography course in colleges and universities, the study of composition is not 
only the difficulty but also the key point. In the face of complex shooting objects, it should learn to accept or reject, retain the useful materials for the theme and abandon the useless subjects, so as to make the picture form a harmonious, unified and changing composition form.

In short, composition is to make the best layout of people, scenery and things according to a certain theme. Making the best layout in the picture is an important form of shaping image, expressing theme and transmitting artistic conception. In the teaching of photography course in colleges and universities, if students want to shoot excellent works, it must cultivate their composition and aesthetic ability. First of all, it needs to understand the evaluation standard of excellent works. Standard is the premise of targeted theme creation. Summarize, refine and choose many shooting objects, picture works with distinctive theme and beautiful composition can be photographed.

\section{CRITERIA FOR GRADING EXCELLENT PHOTOGRAPHIC WORKS}

\subsection{Distinct Theme and Precise Conception}

To cultivate students' composition ability, first of all, students should clarify the theme of photography creation. In photography creation, the word "conception in front of photography" means that it should make an intention before shoot, and "conception" is the theme of the work. An excellent work must have a clear theme at first. In photography, whether the theme is clear and meaningful is an important basis for judging the value of photographic works. Therefore, the composition of photographic works should follow the needs of theme expression, arrange and combine the elements of the picture according to certain artistic laws, and form composition works of with primary and secondary, clear primary and secondary, contrast, cadence and rhythm, moderate simplicity and complexity, dense without space. Therefore, in photographic composition, any picture element must obey the needs of theme expression. The theme mining of photographic art creation comes from social life, which is the photographer's high generalization and refinement of social life. An excellent photographic work not only contains the photographer's passion and creativity, but also contains the photographer's cognition and perception of social life. Therefore, the most important thing of excellent photography is clear theme and accurate conception. The viewer feels the photographer's creative intention in aesthetics, so as to resonate with the photographer. For example, the photography Hope Project series shot by photographer Xie Hailong is a series of works for hope project in the 1990s. Through capturing the moments of children's life and learning, it reflects the children's desire for knowledge in poor areas with a distinctive theme.

\subsection{Highlight the Subject and Establish the Visual Center}

In the picture composition, setting up a prominent and eye-catching visual subject is the second basic element to constitute the excellent photographic works. The performance of the theme depends on the support and realization of the subject, and the prominent picture subject is the best guarantee to realize the visual tension [2]. When observing, choosing and locking the shooting target in photography, the refinement of the subject is a compulsory course for the photographers. Especially in news and documentary photography, the connotation and depth of the subject is often the key contributor to the success or failure of the work. Therefore, when designing the picture composition, it should focus on "highlighting the subject of the picture" and establish the visual focus as the thinking focus. The establishment of visual focus in the picture belongs to the category of picture composition form. It should make full use of and mobilize the formal factors such as point, line, surface, shape, space position and size of each modelling element in the picture. It also should use the visual factors such as virtual reality, light and shade, layout and so on between the shapes to draw the visual center of the picture and the attention of the viewer to the subject. In this way, the visual focus of the whole picture is established. If the elements in the picture are disorderly and the subject of the picture is not determined, it is bound to weaken the theme expression ability.

\subsection{Simple and Interesting Composition}

In the actual shooting process, students are often in a hurry in the face of a wide variety of subjects and have on idea on choose. Many elements will be stacked on the picture, which seriously affects the expression of the picture theme. Excellent photography composition should be concise and interesting. The so-called concise refers to eliminating and compressing all factors that distract attention and weaken the picture theme, and only retaining the picture elements that lead the sight to the subject [3]. Make The picture should concise but not simple, simple but not monotonous, concise and interesting.

In order to better express the theme of the picture, there should be an interest center in the picture. This interest center may be people or things. Photographers highlight the interest center through all modeling means and elements such as composition, light, color and tone. In terms of composition, after careful arrangement and layout, the photographer arranges the interest center in the most eye-catching position in the picture, and other elements are used as a useful and necessary supplement 
to the interest center. For example, Bresson's early masterpiece Children in Sville Town was shot in 1933. The composition of it is simple and full of form. The static, large and broken white walls and children's expressions and gestures form a strong visual impact. The children's posture and expression stand out from the background. Bresson's early photographic works mostly used frame composition. Frame composition can effectively segment the picture by frame, which cannot only increase the sense of space and hierarchy, but also increase the story of the works.

It cannot only show a better sense of space, but also show the three levels of the frame, the frame itself and the viewer.

The combination of the subject of visual focus and the interest center, on the one hand, is conducive to guiding the viewer's interest to the aesthetic direction of the creator. On the other hand, it can integrate the visual focus into the aesthetic taste, so that the form has the aesthetic theme. The beautiful form also increases the interest, and the artistic appeal of the work is strengthened [4].

In short, looking at many excellent photographic works in the history of photography, they are different in theme and picture form. However, after careful study, it will find that they all have common characteristics, which must be distinctive theme, prominent subject and concise picture. These three are the basic conditions that excellent photographic works should possess. Therefore, in the process of undergraduate photography practice, take 3-5 groups as units for shooting creation, students can choose the theme to be expressed according to their group interests. The shooting scheme will be formed. The expression theme and picture style characteristics in the shooting scheme should be set. The excellent photography works with similar styles also should be collected and sorted out. At the same time, the keywords and elements contained in excellent photographic works, as well as the root of the formation of picture style should be analyzed and refined. The characteristics of the picture form with distinctive theme, prominent subject, concise but not simple in excellent photographic works are more profound and clear. In the process of analyzing and completing the planning, students' aesthetic ability and composition ability will be imperceptibly improved.

\section{THOUGHTS ON IMPROVING THE ABILITY OF COMPOSITION CREATION}

The only way for undergraduate photography teaching is to see more and think more, and gradually improve horizons and aesthetic ability. Learning the law of formal beauty of artistic creation is also the top priority, however, it is more important for students to master the control and design ability of picture composition. In photography creation, there are many kinds of shooting subjects, such as scenery photography, product photography, portrait photography, documentary photography, etc. The composition objects of different photography subjects are also very different, which is difficult to grasp. However, from the role and position of various elements in the picture, it can roughly divide them into four parts: subject, companion, environment and color. By grasping the role of the four elements in the picture, it can orderly arrange their position, light and shade in the picture according to the performance theme, so as to form a work with primary and secondary, clear primary and secondary, and far-reaching artistic conception. In this round, a large topic "My --" is set as the performance theme. Each group selects the specific performance subject according to their personal preferences. Through the combination with the application of photography technology aperture and depth of field, students can master a variety of composition forms of the subject in different positions of the picture.

\subsection{Visual Center of Photographic Picture - Subject}

In photography, the subject is the most important factor in the composition of the picture, the carrier used to explain the theme intention, and the visual center and structural center in the picture. The subject can be one or more objects, and other companions should closely surround the subject, perfectly set off the theme and highlight the core position of the subject through light and shade, contrast, position, size and other factors. Therefore, in photography teaching, it should train students' composition ability and strengthen the ability to highlight the central position of the subject in the picture through various picture composition forms. There are the following ways:

\subsubsection{Place the subject into the visual center}

In the picture composition, the subject in the picture is directly presented in an eye-catching and clear structural form through classical composition methods such as golden section, trisection, central focus and so on. In the composition, the subject is placed in the most prominent position with most concentrated light, and the subject is placed in the visual center of the picture, so as to highlight the theme and express the author's creative intention.

\subsubsection{Highlight the subject by guide line}

Learn to use the guide line. The guide line is a photographic composition term. The meaning of guide line is, when the photographer constructs the picture, through the design of the guide line (such as river, line of sight, road, fence, etc.), the audience's line of sight is attracted to the visual center - the subject in the picture. 
In the students' practical work shooting, try to correctly use the composition form of the guide line to emphasize the center of the picture, create the vertical feeling of the picture and highlight the artistic conception of the work. It also makes the interesting picture and increases the sense of cadence and rhythm.

According to different shooting themes, there are many forms of picture guide lines. Each guide line will bring special visual feelings to the picture and convey different picture interests. Common types of guide lines includes: Parallel guide line. Find parallel guidance in the picture. It generally refers to the horizontal or vertical lines in the picture, which are used to convey the sense of calm and tranquility. It is a composition form often used in landscape photography.

Converging guide line. Generally, the meaning of converging guide line is multiple lines in the picture converge at a certain point in the picture. The certain point becomes the visual center. Converging guide line plays a role in strengthening and enhancing the impact of the picture, so as to deepen the viewer's impression.

Staggering guide line. It refers to structure picture through the interleaving of multiple lines in the photographic picture, and enriches the picture through the changes of block size and color. Staggering guide line can increase the cadence and rhythm of the picture.

Hiding guide line. $t$ refers to that there is no obvious line guidance in the picture, and formed hidden lines with the help of other elements, such as the person's sight, gestures, the virtual and real changes of light and shadow. It aims to guide the viewer's sight to pay attention to the main image in the picture and increase the interest and sense of space of the picture.

\subsubsection{Highlight the subject by artistic techniques}

In the process of students' practice of photography, multiple subjects often appear in the same picture at the same time, and there is no obvious difference in their visual characteristics. The subject, companion and environment are integrated. If they are too unified, the subject will not be prominent and the theme expression will not be clear, which will confuse the creative intention and produce unsuccessful work. Therefore, when constructing the picture, it can choose and organize the picture through the general law of artistic form beauty. For example, through art law processing techniques, such as the comparison of the subject's position before and after, the light contrast, the color contrast, dynamic and static contrast of the object, the virtual and real contrast between pictures and other, the subject and the companion can set off and rely on each other, highlight the subject of the picture, deepen the theme artistic conception, and increase the diversity and interest of the composition.

\subsection{Indispensable Visual Element - Companion}

In the photographic composition, in order to better express the theme and reflect the creative intention, in addition to the subject, there are other objects cooperating with the subject to form a certain picture scene atmosphere. Objects can set off the subject's personality characteristics and render the picture atmosphere. These objects are collectively referred to as companions. In students' practice shooting, it is also very important to choose the companions and grasp the position. The main functions of companions are usually as follows:

The function of illustration. Companion mainly explains and illustrates the structural components and functions of subject.

The function of setting off. The companion can highlight the visual center of the subject through elements such as position placement and color matching.

Set off the atmosphere. Companion can set off the atmosphere and increase the artistic conception of the picture through visual elements such as color brightness, size and so on.

Balance picture. In the composition of photographic picture, sometimes the subject is too large or too small. At this time, the picture can be adjusted by adding the form of companion. Through the arrangement and combination of the subject and companion, a composition form that reflects and echoes each other is formed, so as to balance the picture and make the picture full of cadence and rhythm.

Extend artistic conception. When shooting people or animals, in order to increase the interest of the picture, the companion can be placed outside the picture. The viewer can lead attention to the outside of the picture through the hiddenness, such as hiding guiding lines in the picture, including sight and gesture, so as to give the viewer a space for reverie. Making the work with a broader space extension in content and form of expression, it is conducive to the extension of artistic conception.

\subsection{Sharp Weapon for Creating Atmosphere - Environment}

In the composition of photographic pictures, in addition to the subject and companion, there is a very important component - environment. The existence of environment is a beneficial supplement to the subject and companion, and it is an indispensable and important factor. Environmental factors play a vital role in setting off the picture atmosphere, creating the picture artistic conception and deepening the theme expression. Any photographic work is inseparable from the role of environment. Different shooting themes have different subjects and different environmental atmosphere. Therefore, in the teaching and creation of undergraduate photography art, coordinating the relationship between the subject and the background environment is also a very 
important round in undergraduate photography teaching in colleges and universities. The good use of environmental factors cannot only render the atmosphere of the picture, but also increase the richness and hierarchy of composition form. The composition of the picture by using environmental factors generally carries out shooting practice from the two aspects of foreground and background.

Foreground refers to the subject in front of the subject. Due to the perspective principle, near big far small, the foreground is relatively large in the picture and the virtual focus effect is often processed. The foreground of the virtual focus is in sharp contrast to the clear visual effect of the subject. Therefore, the existence of foreground can increase the picture depth and enrich the picture level in the composition.

The charm of the foreground lies in the visual contrast between the foreground object and the subject to increase the expressiveness of the visual language of the picture. The contrast between the foreground and the subject can be strengthened through plastic arts rules, such as large and small, high and low, sparse and dense, light and dark, dynamic and static, gathering and dispersion, so as to increase the expressiveness and appeal of the picture. The object as the foreground should be selected according to the needs of students for shooting topics. Generally speaking, the foreground should be conducive to expressing the theme, highlighting the subject and enhancing the atmosphere of the picture. Beautiful flowers and plants or decorative doors, windows and other objects are usually used. The use of different foreground plays different roles in the picture. For example, in the composition of Mark Lubu's photographic work Old Beijing, the Chinese classical door and window frame structure is used as the foreground, and the pane segmentation method is cleverly used to divide the picture into six independent spaces. Some character contents of it in each frame are also independent chapters. Each frame has an independent expression language and can exist as an independent picture. The combination is also very coordinated. The whole work is engraved with the era mark of old Beijing, which gives people the beauty of vicissitudes and history. Background refers to the subject behind the subject, which is used to render the atmosphere and set off the subject. The background plays the following roles in the picture composition: (1) highlight the structural shape of the subject to make its external contour more prominent; (2) render the environmental atmosphere of the story and explain the background of the event; (3) complete composition, the use of background can increase the depth and space sense of the picture, and balance the picture. Therefore, in the composition of photographic picture, the selection of background is also the key to the success or failure of a work. An appropriate background plays a very important role in shaping the subject image, promoting the expression of theme connotation and rendering the environmental atmosphere. The background of disharmony with the performance theme and disunity with the subject will inevitably make the theme of the work unclear and confuse the viewer's cognition, so it cannot be called a good work.

\subsection{Distinctive Visual Elements - Color}

As the saying goes, "see color from a distance, see flowers from approach", human love for color is innate. As the language and important means of expression of visual art, color has been widely used in artistic creation [5]. The role of color in photography is obvious. It can balance the picture, emphasize the subject, express emotions, and give people psychological feelings in the most intuitive way. In photographic composition, in addition to the structural combination picture through various elements such as subject, companion and environment, color can also become the visual focus of the structural picture. When two or more colors are juxtaposed on the same picture, they will show different visual feelings and personality differences due to the different hue, saturation, purity, area, position, shape and light and dark levels of color. It is the contrast and change between colors that makes the combination and matching of adjacent colors form a picture composition form of contrast or harmony. Pictures with appropriate color matching can always stand out from many works. In the composition of photographic picture, color has the following functions:

\subsubsection{Balance the picture with color}

As the regulation of image on human retina of the length of light wave, the color itself will show the visual deviation of weight, distance and size. For example, light color, solid color and warm color of objects of the same size look lighter, closer and larger than dark color, turbid color and cold color. Therefore, in photography creation, it should use this subjective feeling of color to balance and strengthen the picture space.

\subsubsection{Highlight the subject with contrast color}

In the composition of photographic picture, the picture composition can be reasonably arranged through the contrast between colors, such as color temperature, light and shade, turbidity and so on, so as to highlight the subject and achieve a more "bright" expression intention. It should be noted that the contrast of colors is most obvious only when the purity is the highest. If the lightness and purity of color are improved or decreased, the contrast effect between colors will be weakened and tend to be harmonious [6]. 


\subsubsection{Enhance artistry by color blocks}

In abstract photography, lines and colors are often used to segment pictures to form abstract photography works with great artistic characteristics and interest. It is also a style feature often created by photographers. When using color structure and segment picture composition, it is necessary to reasonably choose and summarize the color blocks of the structural picture, form symmetrical, staggered, thick and light and other structural forms visually, and strengthen the cadence and rhythm of the picture. Different angles, colors and composition make distinctive photographic works.

\subsubsection{Render emotions by color}

After being stimulated by color, people's vision causes psychological differences in the cognition of cold and warm colors, and then produces associations. Therefore, color forms a positive or negative symbolic meaning. In visual design, more is the use of color symbolism. For example, black gives people a sense of solemnity, mystery and depression. When there are too much black in the picture, the picture will show a sense of stability and depression. White gives people a sense of cleanness, purity and simplicity, and the bright light color picture gives people a sense of tranquility and softness. Red represents enthusiasm, sunshine and restlessness. The structural picture based on red gives people a warm and gorgeous feeling. Therefore, in photography creation, it should make full use of the symbolic significance and psychological hint of color to structure the picture, set off the subject, increase the visual impact, and further highlight the theme of the work. In the composition of photographic pictures, countless colors are used, but generally speaking, the principle to be followed is the color matching principle of" see coordination in comparison and see comparison in coordination ".

\section{CONCLUSION}

Photography course plays an important role in art education and improving undergraduate cultural quality education. The quality of photography composition is the key to the success or failure of works. Through the demonstration in the context of this work, the particular importance for students to understand the evaluation criteria of excellent photography works through case analysis and practical homework in photography teaching is understood. Ingenious conception, distinct theme, highlighting the subject, establishing visual center, concise composition and full of interest are essential prerequisites for an excellent work. Only a clear understanding of standards can be targeted in photography creation. Mastering the evaluation criteria of excellent works is a prerequisite for improving students' composition and creative ability. Secondly, students' composition creation ability should be improved by strengthening practical composition practice. Creative composition training should be carried out for the theme of the work and the subject of the visual center of the picture. Through composition techniques of using hiding guide lines, color relationship arrangement, strengthening of artistic treatment by color blocks, the subject will be highlighted and the visual center will be found. Train composition ability with theme, steps and pertinence. Making students master the visual language transmission of different composition forms and use them creatively, therefore, students' creative ability of picture composition and artistic literacy will be improved.

\section{ACKNOWLEDGMENT}

This work was supported by the Classified Development Special Line - Teaching - Undergraduate Discipline Competition 2021 (Project No.: NHFZ 20210180/006).

\section{REFERENCES}

[1] Animation Scene Design- -Composition Skills. URL:

http://cache.baiducontent.com/c?m=9f65cb4a8c8507 ed4fece763105392230e54f7356186da1f68d4e419ce3 b4603506695ba22211306d5c47a6 (accessed on 1st December 2021).

[2] Learn photography and camera must know: What is an excellent photography work? URL:

http://www.zyrykbiandao.com/datum/2445.html (accessed on 8th December 2021).

[3] Perfect scenery photo 10 elements. URL: http://www.doc88.com/p\%2D25229055349736.html (accessed on 10th December 2021).

[4] Xiaofeng image life aesthetics. URL: http://m.toutiao.com/i6818364542095983116/ (accessed on 1st December 2021).

[5] On the technique of expression in documentary photography. URL: https://m.ourlunwen.com/show115-90175-1.html (accessed on 11st December 2021).

[6] What are the skills and standards of photography composition? URL:

https://www.zhihu.com/question/22107626/answer/5 23482020 (accessed on 21st December 2021). 